\title{
Climate Change Shocks Sensitivity Index of Smallholder Farmers Engaged in Farming and Non-Farming Activities in Kinakomba Ward, Tana River County, Kenya
}

\author{
Peter Ndegwa* Andrew W. Wamukota Annie H. Ong'ayo \\ Department of Environmental Studies-Community Development, Pwani University, P. Box 195, Kilifi
}

\begin{abstract}
Understanding the future of smallholder farmers of Kinakomba Ward in Tana River is critical to the design and development of policies. One of the major concerns is establishing how sensitive these farmers are to climate change shocks. This study sought to determine sensitivity index of smallholder farmers that rely on rainfed agriculture and nonfarming activities to climate change related shocks with the intent of formulating appropriate programmes and policies. A descriptive survey research design was used. Stratified random sampling was employed to select 390 households. The qualitative and quantitative data collected using questionnaires was analysed by use of metric of sensitivity and chi-square goodness of fit test. The study revealed that smallholder farmers who relied on farming activity alone had a sensitivity of $43.17 \%$ to climate change related shocks while those who rely on non-farming activities had a sensitivity of $36.40 \%$. When the households engage in both farming and non-farming, the sensitivity will increase by $21.20 \%$ due to the interactions between the two activities. Although the sensitivity percentage for the farmers who engaged in the two activities is low, sensitivity was statistically significant $(\mathrm{P}=0.00038)$. Further findings showed that the ratio of farming to nonfarming was 0.58 and those households dependent on farming and engaged in nonfarming was 0.45 and when they engage in both activities at the same time, they were more sensitive at 0.942 . Despite the significance sensitivity to climate change related shocks, farming sector was ranked as more important $(81.5 \%)$ than other livelihood activities. The study concluded that sensitivity of the smallholder farmers to climate change related shocks had a significant influence on their livelihoods. The County Government in partnership with stakeholders develops interventions of adaptation options and empowerment of farmers with skills in diversification of livelihoods options.
\end{abstract}

Keywords: Climate change related shocks, Farming, Sensitivity index, Smallholder Farmers

DOI: $10.7176 /$ FSQM/93-06

Publication date: January $31^{\text {st }} 2020$

\section{Introduction}

Effect of climate change to the livelihood Climate change is defined by the United Nations Framework Convention on Climate Change (UNFCCC) as 'a change of climate which is attributed directly or indirectly to human activity that alters the composition of the global atmosphere and which is in addition to natural climate variability observed over comparable time periods.' The origin of the climate change debate was the international environmental and developmental challenge that led to different initiatives from the publication of the Brundtland Report in 1987 through to the formation of the Intergovernmental Panel on Climate Change (IPCC 1989), the United Nation Conference on Environment and Development (UNCED 1992) in Rio de Janeiro, and the establishment of the United Nations Framework Convention on Climate Change (UNFCC), (NCCRS 2010).

The evidence of climate change is indisputable. In the last decade European land temperature has been on average $1.3^{\circ} \mathrm{C}$ higher than in the pre-industrial era, compared with a global average rise of $0.8^{\circ} \mathrm{C}$. The heat wave in 2010 caused drought in Russia that substantially reduced its grain harvest (European Union Commission 2014). The European Commission (EC) has put in place an EU adaptation strategy which provides a framework for dealing with the current and future impacts of a changing climate. In Kenya since early 1960s, both minimum (night time) and maximum (day time) temperatures have been on an increasing (warming) trend (NCCRS 2010). The minimum temperature has risen generally by $0.7-2.0^{\circ} \mathrm{C}$ and maximum by $0.2-1.3^{\circ} \mathrm{C}$, depending on the season and the region (NCCRS 2010).

According to IPCC (2012) adaptation is "the process of adjustment to actual or expected climate and its effects, in order to moderate harm or exploit beneficial opportunities". So adaptation is an ongoing process which responds to actual or anticipated direct or indirect effects of climate variability and change (Dessai et al. 2009; Berkhout et al. 2006; Berkhout 2012; Lavell et al. 2012). Adaptation has also been defined as adjustments of a system to reduce vulnerability and to increase the resilience of system to change, in this case in the climate system (IPCC 2010).

Africa is likely to be the continent most vulnerable to climate change (Schneider et al. 2007). At the horn of Africa severe drought interrupted seasonal rains for two consecutive seasons, precipitating in the 2011 worst drought in the region seen in 60 years with precipitation of less than 30\% (April to June) of average of 1995 2010 (Eastern Africa 2011). In Sahel region, 15\% of the population experienced a temperature increase of more 
than $1{ }^{\circ} \mathrm{C}$ from 1970 to 2010 . The mean seasonal rainfall is also below the long-term average, and flooding has increased in frequency and severity. With the increasing frequency, duration, and severity of drought conditions across much of the African continent, smallholder farmers are looking for new ways to ensure that their harvests are secured against unpredictable rains (RoK 2013)

In Kenya the 1999 and 2000 droughts caused damages equivalent to $2.4 \%$ of the Gross Domestic Product (GDP). The Stern Report of 2006 predicts that the cost of climate change in Africa could be as high as 7-10\% of GDP by 2100 , whereas a recent study on the economic impacts of climate change in Kenya has estimated that the annual cost of climate change impacts will be in the tune of USD 1 to 3 billion by the year 2030 (NCCRS 2010). Thus Kenya has developed a National Climate Change Response Strategy (NCCRS) also known as the Strategy to address the challenges of climate change locally. The National climate change Response Strategy recognizes climate change as a threat to national development and has presented evidence of its impacts .The changes are attributed to greenhouse gas emissions. Smallholder farmers who rely on rains are very susceptible to climate change shocks. Less than $6 \%$ of all cultivated land in Africa is irrigated, and almost all smallholder farmers are dependent on rain fed agriculture leaving irrigation untapped for them to overcome their vulnerability to climate changes. Therefore for the farmers to bring their crops to maturity, they have to adapt different methods of conserving water and use drought resistant species. Failure to adapt could lead to deprivation, social disruption, population displacement, and even morbidity and mortality. The reality of crop failure caused by drought, severe flooding affects more than 2.5 billion people around the world who depend on subsistence agriculture for a livelihood (FAO 2014).

\subsection{Statement of the Problem}

In Tana River County, smallholder farmers relay either solely on farming or on farming and non-farming activities. The farmers rely on rain to carry out their farming activities. The reliance on rainfed agriculture has in many occasions led to low production consequently leading to food insecurity and worsening of factors supporting food production, including delayed rainfall, flash floods, infertile soils and lack of inputs, various progressive measures have been advanced by the Government and Non-government organizations for farmers to either adopt or adapt so as to address the negative climatic changes that have made the state of food security deplorable (Ndegwa et al. 2015). Despite these progressive measures no study has been carried out to establish the extent to which the smallholder farmers are sensitive to Climate Related Shocks in Kinakomba Ward, Tana River County Kenya to inform the state and non-state actors on appropriate interventions of adaptation options .

\subsection{Theoretical Framework}

The interaction of human activities and social ecological aspects have brought us to the Anthropocene era resulting in the emergence of a complex social-ecological systems (SESs) (Ohl, Krauze \& Grunbuhel 2007). Human activities have disrupted the ecosystem through extraction, transformation and transportation of natural resources for economic gain. This exploitation of ecosystem services has negatively influenced landscape, biodiversity and the ability of ecosystem to continue producing such services. But surprisingly these systems remain stable under pressure from humanity and this is how the theory of Resilience started developing. In this area we are dealing with Sensitivity of smallholder farmers to climate related shocks.

According to Levin et al. (2013) "global problems reflect the collective consequences of local action" reflecting the importance of cross-scale interactions. These problems are hard to solve when the systems behind them are complex adaptive systems (Levin et al. 2013). The theory regarding SES is very useful in managing ecosystems and finding solutions for environmental problems however Levin et al. (2013) say that the concept of SES is challenging to implement in management and policy because they require the understanding of multiple approaches and are thus too complex to model. It is also important to understand the key elements of the structure of a system (Levin et al. 2013). Levin et al. (2013) lists the various implications of viewing SES in the context of solving environmental challenges, including nonlinearity, scale issues, heterogeneity, risk and uncertainty. The long term goal of this framework is increase general knowledge of SES through the study of multiple individual cases (Ostrom 2007, 2009; Hinkel et al. 2015).

This study used the Social Ecological Systems (SESs) theoretical framework initially proposed by Ostrom, (2007). It was built to provide common vocabulary and logical linguistic structure to facilitate understanding of the sustainability of SESs. According to Ostrom (2005) a Framework provides the basic vocabulary of concepts and terms used to construct explanations of a theory. On the other hand a model constitutes a manifestation of a theoretical explanation of the functional relationships among independent and dependent variables important in a particular setting (McGinnis \& Ostrom 2014). The SES framework is designed to identify basic working parts and their relationships to one another.

According to McGinnis and Ostrom (2014) the SES framework is an ontology, in the sense that it defines a language of terms and specifies a series of logical relationships among these terms. In the SES literature slight variations occur in the second-tier governance system variables as Ostrom and Cox (2010) highlight rules, property 
systems and network structures as the key characteristics of governance systems. On the third-tier McGinnis and Ostrom (2014) have expanded the governance system to include private corporations, community-based organizations and hybrid organizational forms that combine aspects of public, private and voluntary organizations. Thus the SES framework offers knowledge relevant to diagnosis of properties of specific SESs to different situations. To apply the SES framework to a particular case three questions are important: what types of interactions and outcomes related to a particular resource system, resource units are most relevant to the diagnostic concerns? What types of actors are involved? Which governance systems influence the behavior of these actors? (McGinnis \& Ostrom 2014).

The research design is key because the researcher selects the cases and what kind of observations of these cases can best provide the interactions needed to be able to draw valid inferences from the research project. Secondly in any application of the SES framework, the researcher selects which variables should be measured and how indicators will be implemented. Thirdly the SES framework facilitates the communication of results across research communities (McGinnis \& Ostrom 2014).

\subsection{Conceptual Framework}

This theoretical framework was conceptualized for indicators focusing on the vulnerability of the smallholder farmers in Kinakomba Ward SESs. Kloos et al. (2015) developed a multi-hazard risk assessment framework looking at potential impacts of single and multiple hazards affecting SES. Garschagen (2014) integrated framework for vulnerability and adaptation analysis. Mansur et al. (2016) did a conceptual model of vulnerability specifically for the urban areas applying it in context of flood risk. Existing methods for indicator-based vulnerability assessment range from global (UN 2009, 2011, 2013), and (Birkmann et al. 2014) to participatory assessments at the local level (Bollin and Hidajat 2006; Asare-Kyei et al. 2015). In Kinakomba Ward the drought hazard was assessed. In this work the Resource System (RS) is the smallholder farming sector and the Resource Units (RU) are the resources harvested by the smallholder farmers. The Governance System (GS) includes characteristics pertaining to the national and county governments and factors shaping rules and governance arrangement in Kenya. These determine incentives and behaviour for Actors (A) involved in the agricultural sector. These are the smallholder farmers, non-governmental organizations, government officials and researchers. The social, economic, and political setting $(\mathrm{S})$ is the Kinakomba Ward context, in Tana River County. The nature and magnitude of drought as well as the vulnerability of the SES determines the impacts experienced by the SES (community) and its sub-systems and also the risk to experience harm (Sebesvari et al. 2016). Hazards might originate within a given SES or could be generated outside an SES. According to Sebesvari et al. (2016) these interactions from outside and SES internal processes might lead to transformations and tipping processes which greatly influence the vulnerability context. This conceptual SES framework aims to synthesize the Sensitivity index on the socioeconomic characteristics of the smallholder farmers in Kinakomba Ward for the social system. The theoretical framework is conceptualized as shown in figure 1.0 below:

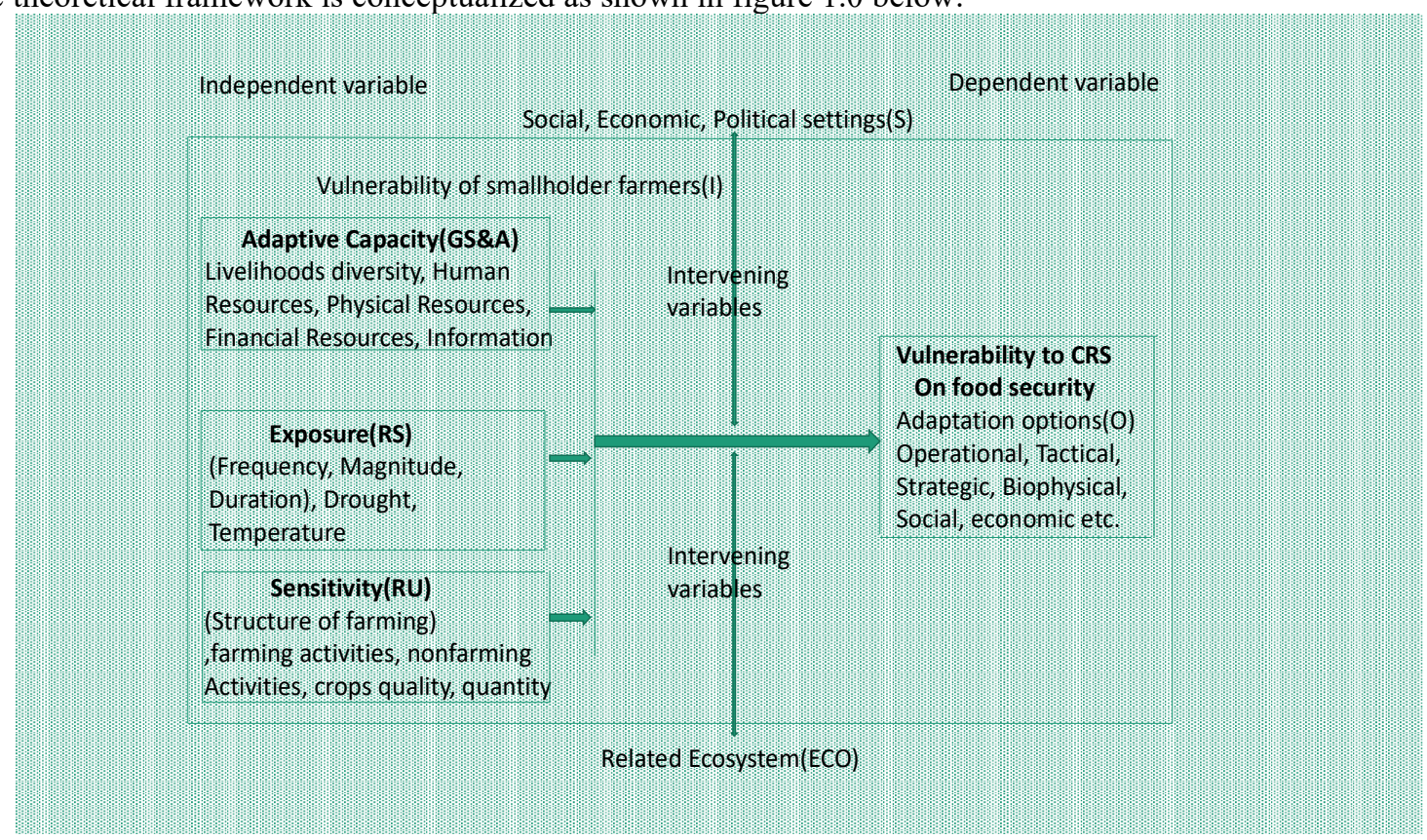

Figure 1 The conceptual framework 
The scope of the conceptual framework

The scope of the conceptual framework is based on vulnerability as the function of sensitivities, exposure and adaptive capacities. This framework is a conceptual model to analyse the sustainability of Socio-Ecological Systems. It is used for the study and comparison of these systems by providing a common vocabulary that enable identify and organize the variables relevant in SES analysis into a multitier hierarchy (Ostrom 2007 \& 2009) and (McGinnis and Ostrom 2014). The Three boxes for independent variable denote first-tier categories RS, RU, GS, and $\mathrm{A}$ are the highest-tier variables that contain multiple variables. The main box containing the interior elements of the figure indicates that the focal SES is a logical whole, but that exogenous influences from related ecological systems (ECO) and social-economic-political settings (S) can affect any component of the SES. These exogenous influences might emerge from the dynamic operation of processes at larger or smaller scales than that of the focal SES. The use of this framework is in three steps as suggested by McGinnis and Ostrom (2014). First step is selection of a focal situation of analysis in Kinakomba Ward where the researchers identified components of the vulnerability system and how there are interacting. Secondly identified the potential variables and their indicators namely that vulnerability is a function of exposure, sensitivities and adaptive capacity. The third step is the analysis of the interactions of these variables and communication and dissemination of the results that were obtained for all the variables. Thus this framework facilitated exchange of knowledge acquired at the end of this process in this case of Sensitivity Index from the entire framework.

Independent variable

The independent variables here represent the causes to climate related shocks. It is these variables that are tested to see if there are the real causes of the climate related shocks. In this case sensitivity index is at the core. Vulnerability to climatic hazards is a function of the interactions between exposure, sensitivity and adaptive capacity which are all determined by the human-environmental conditions and processes. It is recognized that the climate related shocks include increased frequency of severe drought, flood impacts, heat waves, and accelerated glacier retreat, hurricane intensity, and sea level rise (Adger et al. 2007).

Dependent variables

The dependent variables here are the effects of the climate related shocks. It is these effects that are tested to see if there are the output of the climate related shocks. In this case the climate related shocks produce these effects. If the smallholder farmers have a good capacity then their vulnerability is low and the opposite is also the case.

Intervening Variables

There is also the extraneous variable or the moderating factors. These are not the focus of the experiment or survey so there are not tested. Intervening variables are kept constant or monitored to try to minimize their effect on their effects on the experiment. If these are included in a regression as independent variables they aid a researcher with accurate response parameter estimation and goodness of fit but are not under examination. In this case here these are related ecological systems and social, economic and political, settings.

The interaction of variables

The independent variables are measured under different parameters: For sensitivity the parameters are a metric of sensitivity developed using surveys of 390 households, the ratio of farming to non-farming related activities is established and the extent to which households dependent on farming also engage in non-farming livelihood activities establishes linkage between different sectors. Then directionality of linkages between farming and nonfarming activities is also established.

\subsection{Objectives for the Study}

Objective of the study was to determine the sensitivity index on farming and nonfarming activities among the smallholder farmers in Kinakomba Ward. The study was also guided by the following null hypothesis : $H_{01}$ The sensitivity of the smallholder farmers to climate related shocks in Kinakomba Ward is not significantly related to the number of farming and non-farming activities and other social economic characteristics.

\section{Research Methodology}

\subsection{Research Design}

The study adopted a descriptive research design which allowed collecting data in order to answer questions on current status of the subjects of the study. It was used to collect information about people's attitudes, opinions or habits Kombo and Tromp (2006). Kothari (2004) recommended descriptive design as it allows the researcher to describe, record, analyze and report conditions that exist or existed. multi-stage random sampling procedure was used to sample 390 households from accessible population of 3,920 households who are subjected to climate change shocks in Kinakomba Ward. A sample size of $10 \%-30 \%$ of the accessible population is adequate to serve as a study sample (Mugenda and Mugenda 2005). First multi-stage random sampling was used to select Kinakomba Ward out of the fifteen administrative Wards in Tana River County. The selected Kinakomba Ward has five administrative Locations which are Gwano, Jamhuri, Kinakomba, Ndura and Mazuni. In the second stage the researcher selected eleven Sub-Location areas (ESLs) from each of the Locations. The ESLs that was Hara, Maroni 
and Wenje from Gwano Location, Bububu from Jamhuri Location, Majengo and Masalani from Kinakomba Location, Gafuru, Mazuni and Mkomani from Mazuni Location and Bondeni and Handampia from Ndura Location. Sample frame was obtained by listing the villages under each of the ESLs from where samples were taken. The strata was based on the smallholder farmers in the listed village. Stratified random sampling was used to sample households to participate in the study. The $10 \%$ of the households sampled was proportionately distributed in the strata and calculated as shown in Table 1.0.

Table 1.0 Sample Frame

\begin{tabular}{|c|c|c|}
\hline Location & $\begin{array}{l}\text { Number } \\
\text { households }\end{array}$ & $\begin{array}{l}10 \% \text { of accessible populationSampled households }(10 * \text { of total } \\
\text { households }\end{array}$ \\
\hline Gwano & 952 & 95 \\
\hline Hara & 322 & 32 \\
\hline Maroni & 229 & 23 \\
\hline Wenje & 405 & 41 \\
\hline Jamhuri & 654 & 65 \\
\hline Bububu & 654 & 65 \\
\hline Kinakomba & 912 & 91 \\
\hline Majengo & 614 & 61 \\
\hline Masalani & 297 & 30 \\
\hline Mazuni & 542 & 54 \\
\hline Gafuru & 256 & 26 \\
\hline Mazuni & 128 & 13 \\
\hline Mkomani & 159 & 16 \\
\hline Ndura & 842 & 84 \\
\hline Bondeni & 492 & 49 \\
\hline Handampia & 352 & 35 \\
\hline Total & 3,902 & 389 \\
\hline
\end{tabular}

Households were selected by firstly using 10 landmarks i.e. Mosque, Church, Shop, school, Village water point, Posho mill, Village meeting baraza park, junction, electricity pole and Chief's camp and then from each point visiting households until 6 to 10 completed interviews were achieved. At the household level, the interview was with the head or spouse ensuring adequate representation of women.

\subsection{Study area}

The study took place in Kinakomba Ward, Galole Sub-County of Tana River County. Tana River County is subdivided into three Sub-Counties of Bura, Galole and Garsen with a total area of 35,375.8 $\mathrm{KM}^{2}$ $(13,658.7$ sq. miles) whereby Trust land forms the bigger portion of the County with over $90 \%$ of the land. Galole Sub-County has four Wards of Wayu, Chewani, Mikinduni and Kinakomba. Kinakomba Ward is 556.9 square KM with 5 locations and 11 sub locations.

Kinakomba Ward has a population of about 18,000 people $(3908 \mathrm{HH})$ which is about $7 \%$ of the total population of the whole County. The Ward as a whole falls within the Coast low land climatic Zone $\mathrm{CL}_{3}, \mathrm{CL}_{4}$ and $\mathrm{CL}_{5}$. These zones are characterized by scarce rainfall ranging between $300 \mathrm{~m}-600 \mathrm{~mm}$ per annum only. The rainfall is erratic and unreliable resulting in persistent moisture stress in the soil profile. It is characterised by a flood plain along the banks of river Tana prone to flooding whenever the river bursts its banks. Apart from river floods the area is also sometimes affected by floods from the hinterland through seasonal rivers. The community lives in the floods plain and cultivate on the river banks making them very vulnerable to flash floods disasters because they have left the ground bare and the river banks are eroding at an alarming rate causing the river to change its course in many places frequently. The floods disasters experienced in Kinakomba Ward are on annual basis causing untold suffering, displacement of households and death of livestock. Being also in a Semi-Arid Area the community is confronted by immanent, persistent and prolonged droughts every second year and the frequency is increasing fast. The weather condition exhibits very high evaporation demand. From wood-head maps, the average evapo-transpiration during the dry and sunny months with a crop factor of 0.9, is 5.2mm/day (CIDP II 2018-2022). Average annual temperatures are about $30^{\circ} \mathrm{C}$ with the highest being $41^{\circ} \mathrm{C}$ around January-March and the lowest being $20.6^{\circ} \mathrm{C}$ around June-July.

The area is between $70-100 \mathrm{~m}$ above sea level. Slopes are within the range of $0.05 \%-0.15 \%$ with local surface undulations. The soils range from sandy, dark clay and sandy loam to alluvial deposits. The soils are deep around the riverine environments but highly susceptible to erosion by water and wind. Soils in the hinterlands are shallow and have undergone seasons of trampling by livestock, thus are easily eroded during rainy seasons (CIDP II 20182022). The vegetation ranges from scrubland to thorny thickets within the riverine area. Main crops grown are mangoes, bananas, maize, green grams, cowpeas, tomatoes, vegetables and melons while main livestock kept are 
cattle, sheep and goats. The study site is as shown in Figure 2 below.

\subsection{Data Collection Instruments \\ 2.3.1 Questionnaire}

In this study, the researcher used questionnaires and an observation checklist to collect data. Three sets of questionnaires were developed and administered to the respondents. The researcher developed these questionnaires for the purpose of gathering information from respondents (Mugenda and Mugenda 2010). Observation overcomes one of the key disadvantages of interviews and questionnaires that is, that the responses provided may not be accurate (Dawson 2009). The questionnaire for the smallholder farmers had two sections structured and semi structured all covering sensitivity.

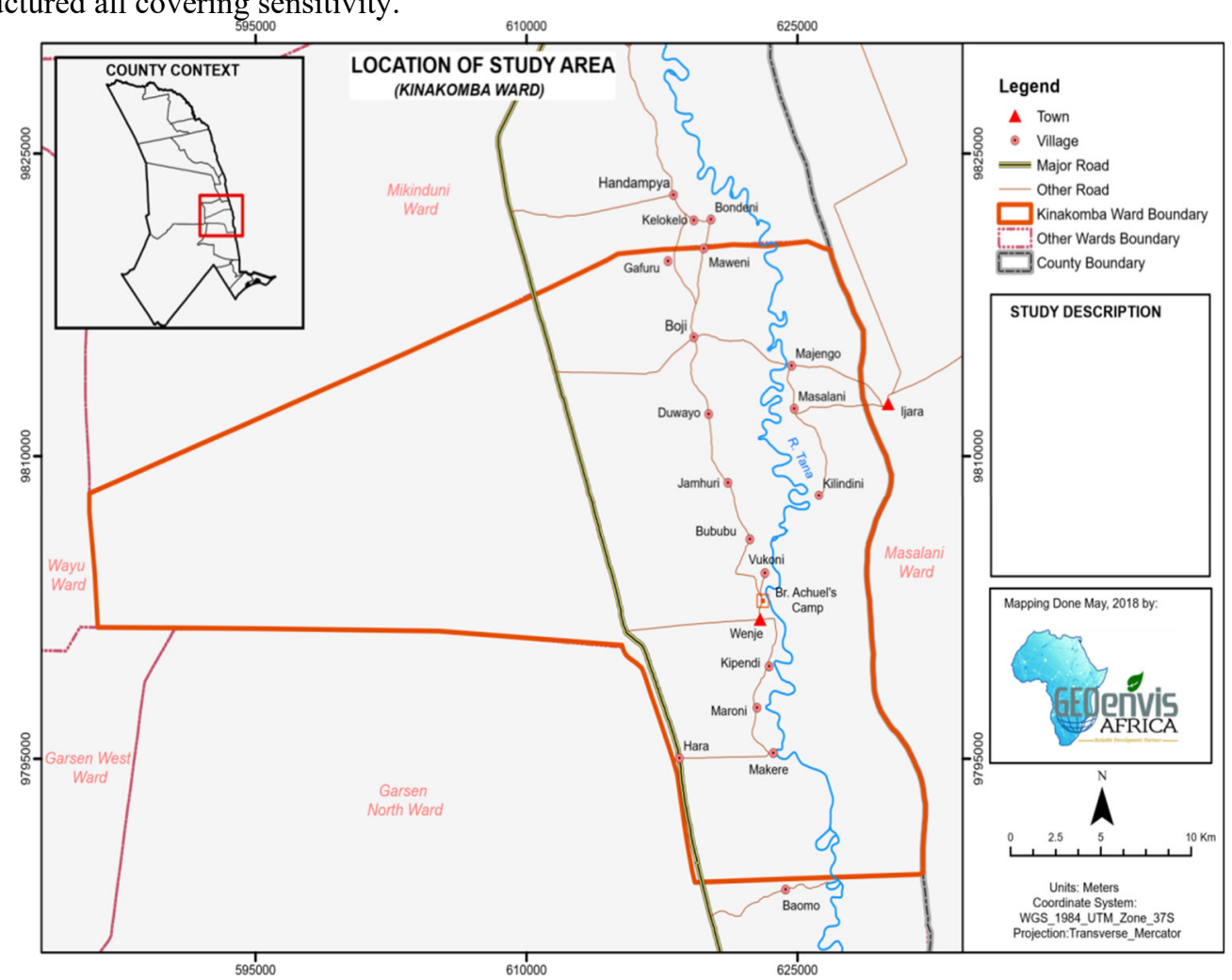

Figure 2 The map of Kinakomba Ward

Semi structured questions assisted in generating in-depth and explanatory qualitative information. This method allowed flexibility, follow up to original questions and pursuing of new lines of questioning, two-way interaction and facilitates exchange of information between the interviewer and interviewee making the atmosphere more relaxed. The use of both questionnaires and semi-structured questions is necessary in order to get as much information as possible from the community members. Administration of questionnaire to Key informants was done with people with vast experience and knowledge who can provide extensive insight into biosocio-cultural aspects of the community.

\subsubsection{Focus Group Discussions}

Focus Group Discussions was developed and used to collect information on Sensitivity. The tool allowed for indepth probing while the observation schedule was prepared and shared. This involved transect walks across the village and interacting with the villagers freely. This gave the feeling of the situation as is on the ground.

\subsection{Validity and Reliability of Research Instruments}

The validation of the instruments were determined before being used for data collection in the field. This reduced biasness of the data collected (Abbott \& Bordens 2011). This was done by experts from the department of Environmental Studies- Community Development of Pwani University, to assess the face, content and construct validity of the instrument. A pilot study was done prior to collection of data to test the reliability of the instruments . A test-retest technique was used to improve the questionnaire, semi-structured questions and focus group interviews. Piloting was carried out for 39 households which make 10 percent of the study sample. According to Orodho (2004) the number in the pre-test should be at least 10 percent of the entire sample. Cronbach's alpha was used to determine the internal consistency of items in the questionnaire to gauge its reliability. According to Cronbach (1957) a coefficient of between $0.7 \leq \alpha<0.9$ is taken to be good while that of $\alpha \geq 0.9$ is taken to be excellent George (2003). 


\subsection{Data collection and analysis}

A letter of approval for the proposed research from the ethical review panel of Pwani University and an introductory letter from Pwani University Graduate School was obtained. Data was collected on the Sensitivity of the smallholder farmers to climate related shocks.

\subsection{Sensitivity Index}

For Sensitivity the researcher developed a metric of sensitivity based on the level of dependence on farming according to (Allison et al. 2009; Marshall et al. 2010). In developing the sensitivity metric, the respondents were asked to list all livelihood activities that bring in food or income to their household and rank them in order of importance. This metric was also narrowed down to the farm and non-farm activities

Occupations were grouped as follows: farming, crop sales, vegetable sales, casual agricultural labour, casual non-agricultural labour, livestock sales (cattle, goats chicken etc.), fishing, skilled trader/artisan, Medium/large business, petty trade (firewood sales etc.), formal salary/pension, remittance, other and 'None' (Cinner and Bodin 2010). To narrow down sensitivity to drought the researcher categorized farm and non-farm sectors (Barrett et al. 2001). With this the metric of sensitivity incorporated the proportion of households engaged in farming. When these households also engaged in non-farm occupations the researcher treated that as linkages between sectors and when the respondents ranked farming higher than say livestock keeping or fishing that was treated as the directionality of these linkages the equation below was used (Cinner et al. 2012):

$$
S=\frac{F}{F+N F} X \frac{N}{F+N F} X \frac{\left(r_{f n / 2}\right)+1}{r_{f n}+r_{n f}+1}
$$

Where $\mathrm{S}=$ sensitivity, $\mathrm{F}=$ number of households relying on farming related activities, $\mathrm{NF}=$ number of households relying on non-farming activities, $\mathrm{N}=$ number of households, ${ }^{r}{ }_{f n}=$ the number of times farming related activities were ranked higher than non-farming activities (normalized by the number of households), ${ }^{r} f$ $=$ the number of times non-farming related activities were ranked higher than farming activities (normalized by the number of households).

The researcher selected four assistants from the local area to ensure local customs are respected. This enabled creation of a rapport with the community. Two weeks were taken to explain the objectives of the study to the community, adequate time was spent explaining the objectives and enough chance given to community for seeking clarification. To minimize biases information notes were taken and later used to enrich the questionnaires. The questionnaires to be used had specific questions with limited answers creating a possibility to get the quantitative data that could be analysed statistically. The meetings took between 3 - 4 hours and they were done in all the five locations with the permission of the area administrator (chief).

\section{Results and Discussion}

\section{Response rate}

The researcher administered 390 questionnaires to household heads within Kinakomba Ward ensuring maximum response rate of $100 \%$.

\subsection{Demographic Characteristics of Participants}

Under this section, background characteristics such as age of the respondent, gender, level of education, occupation, household size are presented.

\subsubsection{Gender of Respondents}

Findings in Figure 3.1 show that majority $(57.9 \%)$ of the respondents in the study were of the female gender while male were $42.1 \%$. The large $(57.9 \%)$ percentage of females which is two third and over one third $(42.1 \%)$ of male gender representation in the sample is consistent with the findings of Ong'ayo and Akoten (2007) who stated that farming among smallholder farmers is practiced by both sexes. They also said that women participated in agriculture because they are the custodians of the food stores and utilization. Since women are involved in farming activities they are sensitive to the functions of food production which are affected by climate related shocks. As women engage in catering they are sensitive to the nutritional needs of their families. Such needs call for budgeting, meal planning and preparation, which all depend on the amount of food in the household store. The involvement of women in farming activities is also because of their desire to support their households. The study is also consistent with the findings of Menike and Arachchi (2016) who state that the agricultural sector is most sensitive to changing climatic conditions which affect agricultural production and farming communities. Further the study agrees with the findings of Lindoso et al. 2012 who state that smallholder farmers are one of the most vulnerable social groups to climate change. Thus climate related shocks are not only having negative impacts on agriculture production of farmers but they also put their household well-being and food security at risk (Alam et al. 2017). The findings also show women are more than men and this is consistent with the Tana River (CIDP II 2018-2022) 
that the ratio of male to female is $99: 100$.

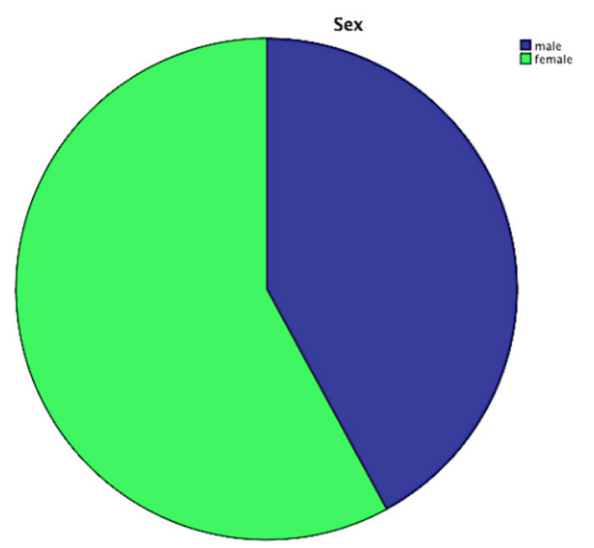

Figure 3.1 Gender of the respondents

3.1.2 Distribution of Respondents by Age

Majority (60.5\%) of the respondents in the study were aged 40 years and below. This two third indicates that most farmers are young people who have energy which, if well used, could bring positive change in agricultural production. This also means the smallholder farmers are less sensitivity to other production factors because of the young average age. The group of children under five, and adults above 65 years old, are categorized into the vulnerable social group sub-component

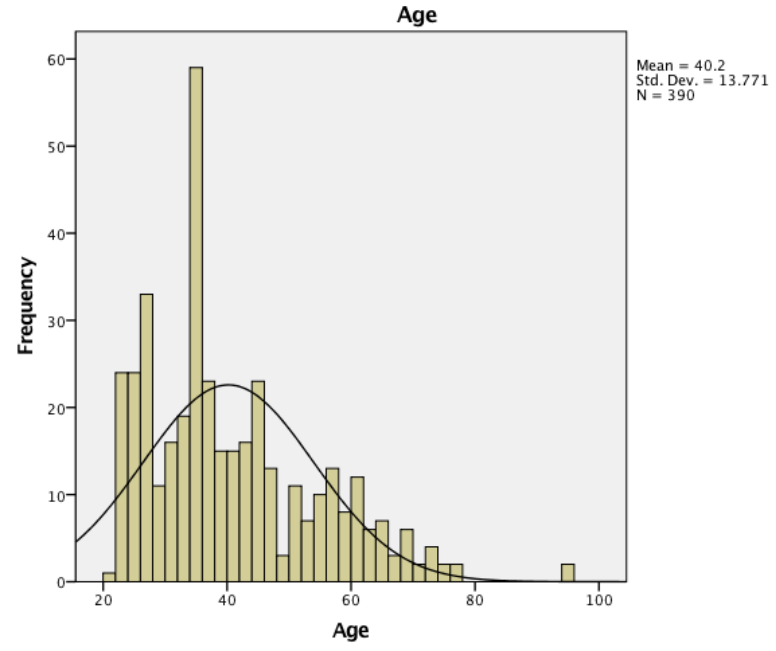

Figure 3.2 Age of the respondents

\subsubsection{Distribution of Respondents by Education}

The respondents were asked to indicate their highest level of academic qualification. Findings in Figure 5 show that majority $(68.7 \%)$ of the participants had primary education as their highest level of education. These findings show that majority of the residents of Kinakomba Ward were lowly educated which is consistency with the Tana River (CIDP II 2018-2022) that indicate the literacy rate as $66.3 \%$ for the County.

Majority $34.6 \%$ had not attended any schooling in their lives. They had not attained any level of education meaning they could not follow well agricultural trainings that would be provided by different stakeholders especially the extension officers. Then $10.3 \%$ had their highest level of education being preprimary school bringing to a total of $44.9 \%$ of illiteracy in the study area. This increases the degree to which the smallholder farmer is affected by the exposure to drought because of lack of different methods that would be applied to reduce the effects of drought or floods most of which would be through training. Yet lack of ability to follow such trainings increases the sensitivity of the smallholder farmer. This is also consistent with Chinwendu et al. (2017) who found that inadequate education, access to resources, poor local institutional capacity and services, and gender were a key factors that shaped vulnerability. Mbakahya and Ndiema (2015) argued that factors such as poverty and hunger, poor health, low levels of education, gender inequality, contribute to

vulnerability. Also Jan et al. (2012) identified factors including the education level of the household head, age of the household head, job experience of the household head, number of employed members of the household all affect the livelihoods of the household. 


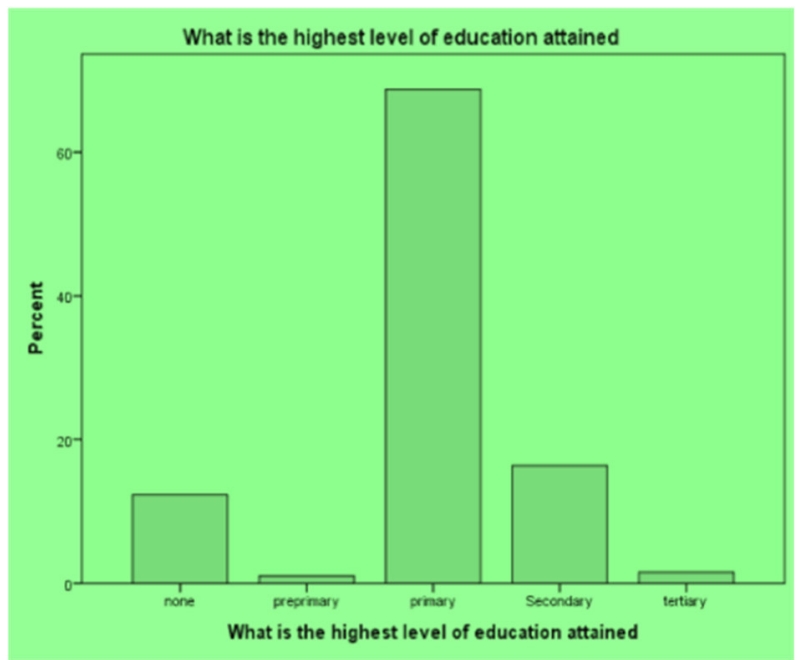

Figure 3.3 Distribution of the respondents by education

\subsubsection{Distribution of Respondents by Occupation}

Majority $(81.5 \%)$ of the participants in the study were farmers. This shows that the respondents in the study were well placed to respond to the research questions on the climate shocks affecting food security in the area. They also ranked farming high at $81.5 \%$ meaning most people in the area depend on farming activities. This high ranking makes the farmer more sensitive to climate related shocks because they may not have anything to fall back to in case of severe drought, frequent flooding nor pest outbreak.

The main job for the smallholder farmers is farming. But farming fails more often than not because of delayed rains, little precipitation, monocropping, little knowledge of farming skills, expensive farming inputs, severe droughts and frequent floods. These leave the farmers with little or no harvest at all making them shift to coping mechanisms that are damaging to the environment including charcoal burning, deforestation and cultivation along the river bank leaving the area susceptible to erosion.

Asked why some of them had left or abandoned farming, they said Farming became expensive because the land was producing less and less because of soil infertility, irrigation using fossil fuel which is expensive and no returns nor breaking even on marketing of the produce from the farms. The produce is barely enough for subsistence and one even gets into debts during the planting season making it very difficult to start the next season thus the farmer is trapped in a cycle of poverty. These are the reasons why the farmers stopped farming because there was no capital and they therefore lost interest.

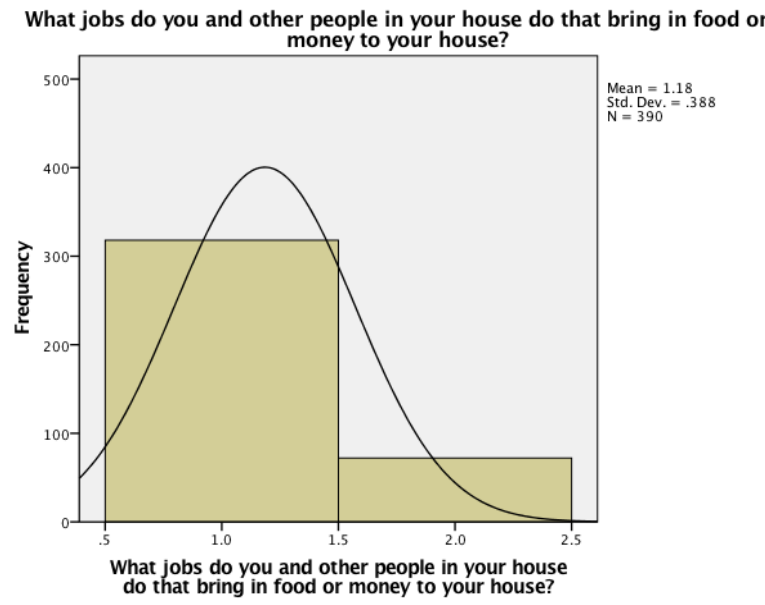

Figure 3.4 Distribution of the respondents by Occupation

The sensitivity of farmers reduces when there is diversification within the farming sector. Thus when farmers engaged in different kinds of farming including kitchen gardening, agroecological approaches, livestock keeping they had something they could fall back to in case of unpredictable climate related shocks. 
Table 3.1 Ranking the jobs according to their importance

\begin{tabular}{|ll|l|l|}
\hline & Frequency & Valid Percent \\
\hline Valid & Farming first & 318 & 81.5 \\
& Non farming first & 72 & 18.5 \\
& Total & 390 & 100.0 \\
& & \\
\hline
\end{tabular}

Majority of the respondents (81.5\%) had an average of four different kinds of occupations meaning they were not relying only on one kind of a job. This reduces sensitivity to climate related shocks even further because the farmers have ways of diffusing the effects of the shocks.

Table 3.1 Number of occupations that the respondents are involved in

\begin{tabular}{|ll|l|l|}
\hline & & Frequency & Valid Percent \\
\hline Valid & Four different & 318 & 81.5 \\
& occupations & & \\
& two different occupations & 69 & 17.7 \\
& one occupation & 3 & 8 \\
& Total & 390 & 100.0 \\
& & \\
\hline
\end{tabular}

The respondents were asked to indicate if they were involved in decision making in their community. Findings in Table 3.3 indicate that Majority $90.8 \%$ were involved in decision making in their community. Ideally this reduces sensitivity of the smallholder farmers to climate related shocks in the sense that there is public participation. When farmers are involved in decision making about their livelihoods it enables them to determine their destiny effectively reducing their most pressing problems. The effects of climate related shocks are best addressed by stakeholders one of the most important being the community itself. This is because it is the community that is directly involved and they who devices survival mechanisms against the impacts.

Table 3.3 Involvement of the respondents in decision making
\begin{tabular}{|ll|r|r|}
\hline & \multicolumn{2}{|c|}{ Frequency } & Valid Percent \\
\hline Valid & yes & 354 & 90.8 \\
& no & 36 & 9.2 \\
& Total & 390 & 100.0 \\
\hline
\end{tabular}

Majority 91\% (Table 3.4) said they were involved in decision making about farming resource use or management. This also reduces sensitivity of the farmers to climate related shocks because resource management is key in reducing the effects of these shocks. When farmers who are organized in groups are aware and informed of what goes on about their produce, how much have been harvested say in their scheme, how much money was made and how the group plans to use the money this empowers the members and reduces their sensitivity to the negative effects of climate related shocks.

Involvement of farmers in decision making is very essential in addressing the attitudes of the farmers. Usually there are two ways of involvement one horizontal and the other vertical. During focus group discussions farmers said horizontally something was being done in the groups. Farmers discuss how to deal with their problems but the problem of attitude is major. Farmers have negative attitudes towards climate friendly crops like the tubers and roots where they said these are crops for the poor. If you give your child cassava or sweet potatoes as packed lunch other students in school would laugh at your child and avoid sharing meals with them thus discouraging them from carrying such foods. This applies to sorghum, millet, yams and sweet potatoes. This attitude increases sensitivity of the smallholder farmers to climate related shocks because while a solution towards food and nutritional security lays in there a negative attitude prevails contributing to food insecurity. Vertically the information from government is not forthcoming on both the advantages of such foods nor training on value addition to such foods. Even policy and marketing of such crops is a pipe dream. Thus the level of sensitivity to crops being promoted is high. 
Table 3.4 Are you involved in decisions about farming resource use or management

\begin{tabular}{|ll|l|l|}
\hline & & Frequency & Valid Percent \\
\hline Valid & yes & 354 & 90.8 \\
& no & 36 & 9.2 \\
& Total & 390 & 100.0 \\
& & & \\
\hline
\end{tabular}

Majority (59\%) (Table 3.5) belonged to four groups while (32.8\%) belonged to three groups meaning they were actively involved in some activities for their livelihoods. These would be different groups ranging from religious, social and financial. Belonging to many such groups reduces the sensitivity of the farmers to climate related shocks like drought because each group could be offering a different alternative of how to get out of the problem.

Table 3.5 Number of groups the respondents belong to

\begin{tabular}{|ll|l|l|}
\hline & & Frequency & Valid Percent \\
\hline Valid & one & 22 & 5.6 \\
& two & 10 & 2.6 \\
& three & 128 & 32.8 \\
& four & 230 & 59.0 \\
& Total & 390 & 100.0 \\
\hline
\end{tabular}

Asked how many meetings they attended within a span of six months majority (92.6\%) admitted they attended six meetings meaning they were very active in their group's activities.

Table 3.6 How are you involved

\begin{tabular}{|ll|l|l|}
\hline & & Frequency & Valid Percent \\
\hline Valid & active & 367 & 94.1 \\
& passive & 23 & 5.9 \\
& Total & 390 & 100.0 \\
\hline
\end{tabular}

Majority 94.1\% (Table 3.6) said they were involved actively. When members of farming groups are active they achieve more and solve most of their daily problems within their groups. A problem shared is almost a problem solved. This makes the level of awareness of their problems very high meaning majority know what their problems are and how they could be solved. Sensitivity is the degree to which the smallholder farmer is affected by the exposure to the climate related shocks like severe drought. These effects reduce when this problem is shared among the farmers and with other stakeholders especially the government so that an immediate intervention is implemented.

Majority $94.1 \%$ said they were involved in community events like celebration and feasts outside their family in the last one year. This aspect allows the smallholder farmers exposure and sharing of different experiences in their daily lives. It also makes them forget for a while their daily stresses caused by drought or floods. This sharing releases pressure of the immediate problems and allows the farmers to begin a new life.

Table 3.7 How many

\begin{tabular}{|ll|l|l|}
\hline & & Frequency & Valid Percent \\
\hline Valid & three to four & 81 & 20.8 \\
& five to eight & 309 & 79.2 \\
& Total & 390 & 100.0 \\
& & & \\
\hline
\end{tabular}

Majority 79.2\% (Table 3.7) attended these events between five to eight times in the year. This would mean the farmers attended at least one event every two months and considering the farming season is between three to four months this was well spread out. This is hoping that such events have a positive effect in a rural community that is not having any other activities that bring them together to share and enjoy themselves. 


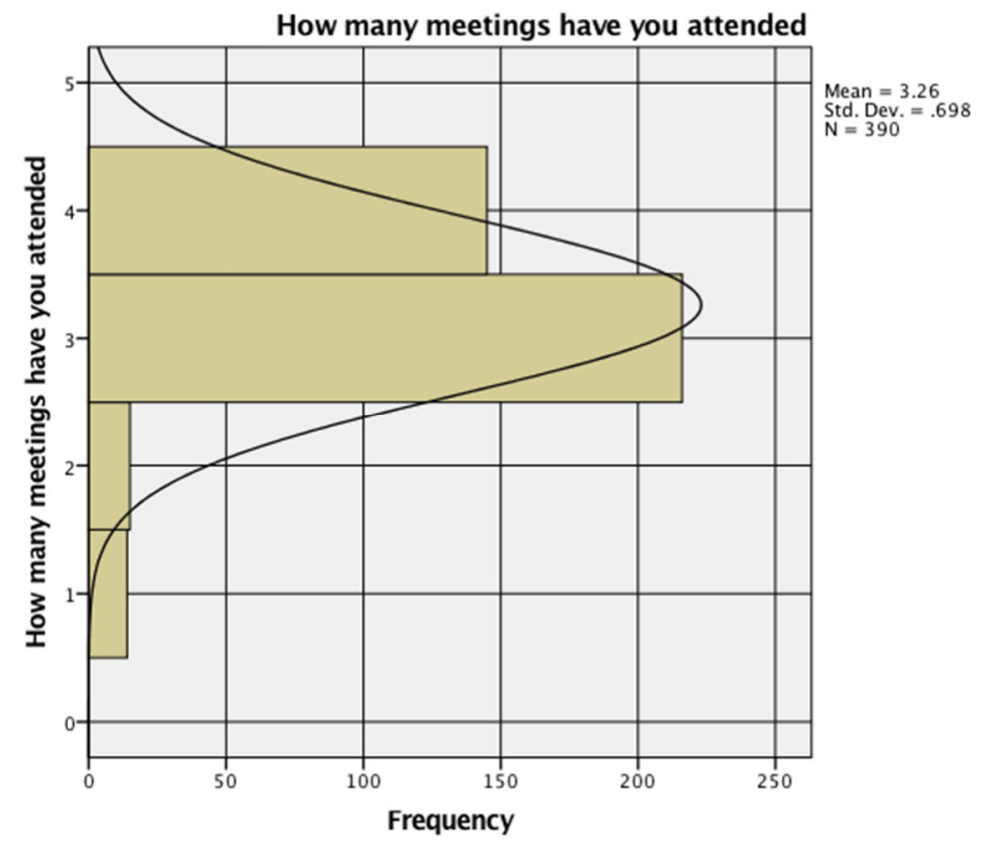

Figure 3.5 Number of meetings the respondents have attended in the last six months Table 3.8 How many meetings have you attended

\begin{tabular}{|ll|l|l|}
\hline & & Frequency & Valid Percent \\
\hline Valid & none & 14 & 3.6 \\
& few & 15 & 3.8 \\
& most & 216 & 55.4 \\
all & 145 & 37.2 \\
& Total & 390 & 100.0 \\
\hline
\end{tabular}

But only $37.2 \%$ (Table 3.8 ) attended all the meetings while majority $55.4 \%$ attended most of the meetings. In a rural setting not attending such meetings is usually the beginning of increasing sensitivity to the farmers because most of their problems are not well articulated and a group solution arrived at by majority.

3.1.5 Access of the Respondents to Credit

The respondents were asked if they have access to credit and the Figure 3.6 below indicates majority (97.4\%) have access to credit.

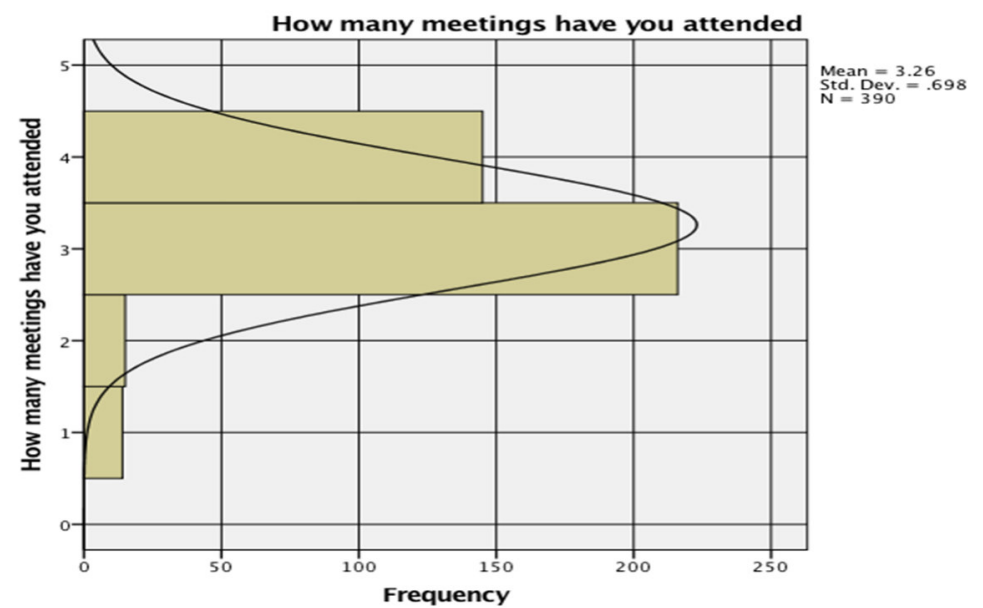

Figure 3.6Access to credit

While majority (84.9\%) got their credit through their respective groups only $3.3 \%$ got their credit through financial institutions directly.

3.1.6 Sources of Income and Employment

The researcher asked the respondents to name all their sources of income and employment and Majority $95.4 \%$ named farming. 
Table 3.9 Sources of income in the households

\begin{tabular}{|l|l|l|l|}
\hline \multirow{3}{*}{ Valid } & Frequency & Valid Percent \\
\cline { 2 - 4 } & Farming & 372 & 95.4 \\
\cline { 2 - 4 } & crop sales & 13 & 3.3 \\
\cline { 2 - 4 } & casual agri labour & 1 & .3 \\
\cline { 2 - 4 } & livestock sales & 2 & .5 \\
\cline { 2 - 4 } & fishing & 1 & .3 \\
\cline { 2 - 4 } & petty trade & 390 & 100.0 \\
\cline { 2 - 4 } & Total & many member & $0 f$ \\
\hline
\end{tabular}

The researcher asked the participants to indicate how many members of their households and which jobs were involved and majority $95.6 \%$ had two persons per activity most of the time.

\subsubsection{Ranking the Important Jobs in the Household}

The researcher asked the respondents to rank in order of importance the jobs they do at their homes and majority $82.6 \%$ ranked farming and $17.4 \%$ other jobs like casual labour and fishing

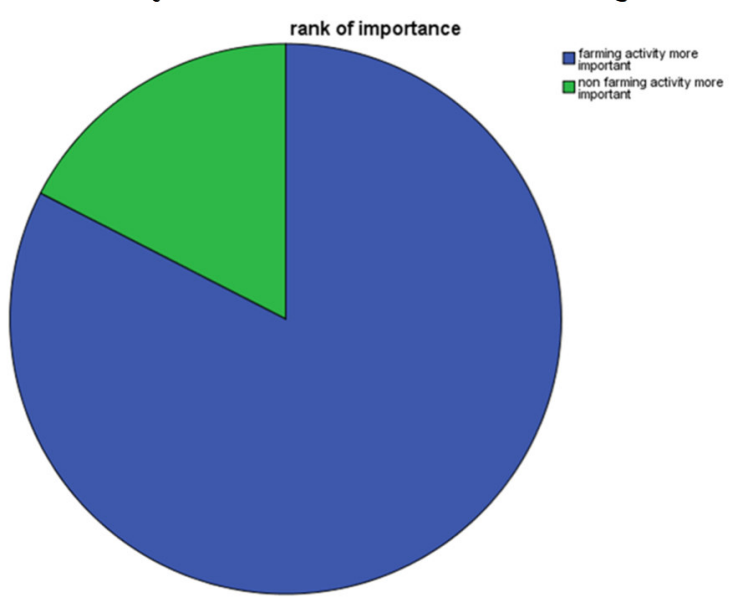

Figure 3.7 Ranking in order of importance

\subsubsection{Sensitivity Analysis}

The researcher evaluated the socioeconomic characteristics of the smallholder farmers in Kinakomba Ward as the main objective. A metric of sensitivity based on the level of dependence on farming was developed according to (Allison et al. 2009; Marshall et al. 2010). This was done using surveys of 390 households living in 18 villages of Kinakomba Ward. Sampling of these households was done using a proportionate sampling design taking $10 \%$ from each village based on the population of the village. The respondents were asked to list all livelihood activities that bring in food or income to their household and rank them in order of importance and majority $(81.5 \%)$ ranked farming as the most important and $18.5 \%$ other jobs like casual labour and fishing.

From Simulation the diagram shows the values of variable in the Tornado chart

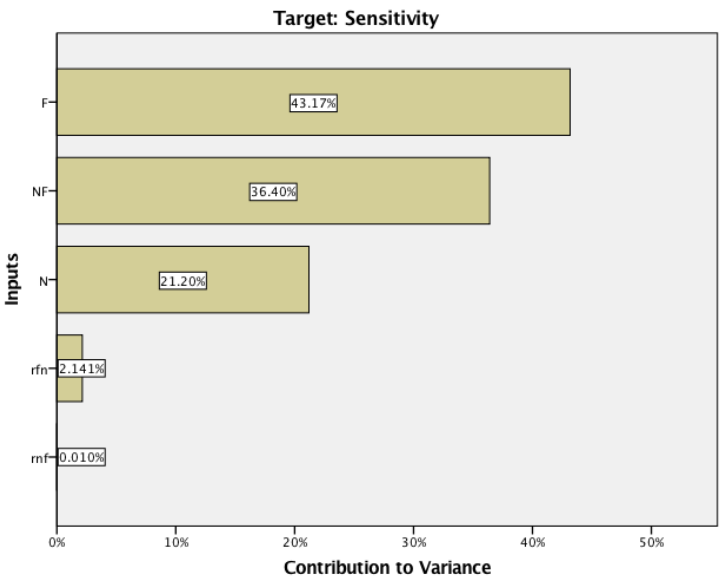

Figure 3.8 Sensitivity model

Variance based sensitivity analysis is a form of global sensitivity analysis Sobol I. M (2001) and Saltelli A. et al. 2008. It works within a probabilistic framework. It breaks down the variance of the output of the model or 
system into fractions or percentages which are attributable to inputs or sets of inputs. From the above Sensitivity model with the five inputs, $43.17 \%$ of the output variance is caused by the number of households relying on farming related activities while $36.40 \%$ of the output variance is caused by the number of households relying on non-farming activities. It also shows that a unit increase in the number of the households will increase Sensitivity by $21.20 \%$ due to the interactions between the two variables. These percentages are direct measures of sensitivity of farming and non-farming activities among the smallholder farmers in Kinakomba Ward. These measures of sensitivity are acceptable across the whole input space globally.

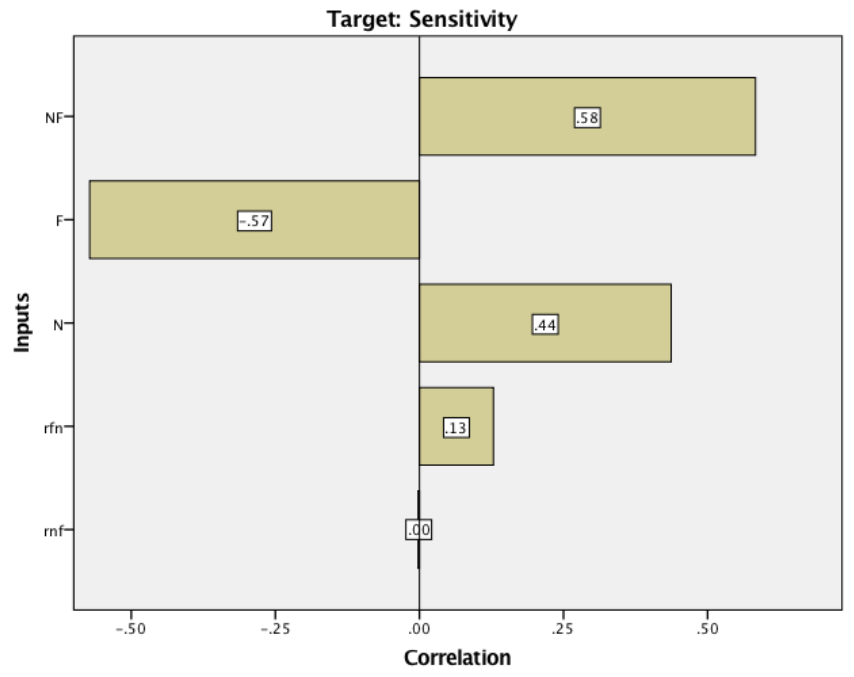

Figure 3.9 sensitivity index

Table 3.2 correlations of the variables Correlations

\begin{tabular}{|l|r|r|r|r|r|}
\hline & $\mathrm{F}$ & $\mathrm{N}$ & \multicolumn{1}{c|}{$\mathrm{NF}$} & \multicolumn{1}{c|}{ rfn } & \multicolumn{1}{c|}{ rnf } \\
\hline $\mathrm{F}$ & 1.000 & .000 & .000 & .000 & .000 \\
$\mathrm{~N}$ & .000 & 1.000 & .000 & .000 & .000 \\
$\mathrm{NF}$ & .000 & .000 & 1.000 & .000 & .000 \\
$\mathrm{rfn}$ & .000 & .000 & .000 & 1.000 & .000 \\
$\mathrm{rnf}$ & .000 & .000 & .000 & .000 & 1.000 \\
\hline
\end{tabular}

Table 3.8 correlations of the variables

Correlations
\begin{tabular}{|l|l|l|l|l|l|}
\hline & $\mathrm{F}$ & $\mathrm{N}$ & $\mathrm{NF}$ & $\mathrm{rfn}$ & $\mathrm{rnf}$ \\
\hline $\mathrm{F}$ & 1.000 & .019 & -.021 & .015 & .014 \\
$\mathrm{~N}$ & .019 & 1.000 & -.008 & .010 & -.018 \\
$\mathrm{NF}$ & -.021 & -.008 & 1.000 & .000 & .001 \\
$\mathrm{rfn}$ & .015 & .010 & .000 & 1.000 & .059 \\
$\mathrm{rnf}$ & .014 & -.018 & .001 & .059 & 1.000 \\
\hline
\end{tabular}

Correlations between simulated inputs may differ from correlations specified for those inputs in the simulation plan.

Substantiating the Equation:

$$
\begin{aligned}
& S=\frac{F}{F+N F} X \frac{N}{F+N F} X \frac{\left(r_{f n / 2}\right)+1}{r_{f n}+r_{n f}+1} \\
& \mathrm{~F}=-0.57 \\
& \mathrm{NF}=0.58 \\
& \mathrm{~N}=0.44 \\
& r_{f n}=0.13 \\
& r_{n f=0.00} \\
& \mathrm{~S}=-0.57 /-0.57+0.58 * 0.44 /-0.57+0.58 *(0.13 / 2)+1 / 0.13+0.00+1 \\
& \mathrm{~S}=0.58 * 0.45 * 1.065 / 1.13(0.942) \\
& \mathrm{Sensitivity} \mathrm{Score}=0.2458
\end{aligned}
$$


The first part in this equation denoted the ratio of farming to non-farming related activities which was 0.58. The second part of the equation denoted the extent to which households dependent on farming also engaged in non-farming livelihood activities which was (0.45). That showed linkage between the two sectors. This term decreases the level of sensitivity when many households are engaged in both occupational categories

The third part of the equation captured the directionality of linkages between farming and non-farming activities (0.942) such that communities were more sensitive when households engaged in farming and nonfarming activities and continued consistently ranking the farming sector as more important (81.5\%) than other livelihood activities. Using this composite metric, we captured some new aspects of sensitivity that at 0.2458 which is about 0.2 to a two decimal point the community has a low sensitivity ratio though sensitivity and occupational dependency can have a number of social and psychological dimensions (Marshall 2010; Marshall and Marshall 2007).

The sensitivity score has three factors. Firstly the fraction of households being engaged in farming related activities, this factor ranges from 0 to 1.0 because each household is engaged in at least one sector and potentially in both and the researcher found out that for Kinakomba Ward the score was 0.2458 . Secondly the ratio of the total number of households to the total number of occurrences of households being engaged in either the farm or nonfarm sector. The ratio here ranges from 0.5 to 1.0 according to Cinner et al. 2012, but the researcher found out that the score in Kinakomba Ward was 0.45 meaning the level of sensitivity decreased when many households engaged in both occupational categories. Thirdly the ranking of occupational importance was also taken into account. This was designed to differentiate between cases when farming is being ranked higher than non-farming and the other way round, the researcher found out that the score for Kinakomba Ward here was 0.942. Since the farming sector was ranked higher at $81.5 \%$, the sensitivity index decreased to 0.2 . And, if there were no linkages whatsoever, the sensitivity score would peak (Cinner et al. 2012).

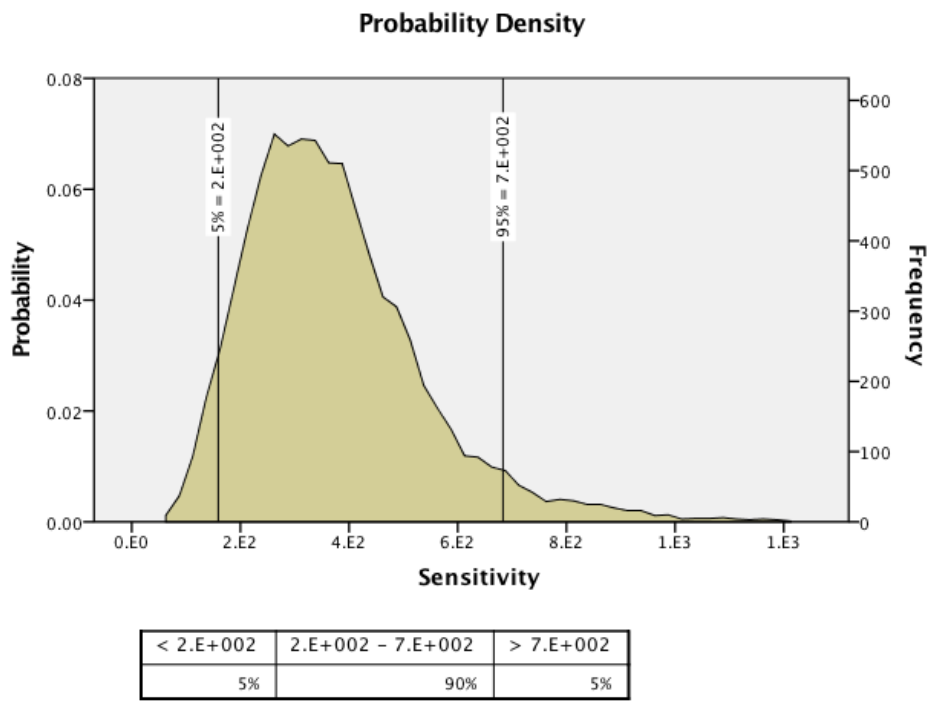

Figure 3.10 Probability density

Using the same formula the researcher was able to establish the sensitivity score for each of the nine villages that the research was conducted. This demonstrates where the sensitivity is higher and guides the policy makers to know how to intervene depending on the sensitivity score. For Vukoni village the score was 0.3470, Maroni village 0.6595 , Makere village 0.3125 , Wenje village 0.6089 ,Kipendi 0.2088 , Bububu village 0.6766 , Majengo village 0.6331 , Masalani village 0.7238 and Mazuni village the score was 0.6525 . From this analysis Masalani village had the highest Sensitivity score of 0.7238 while Kipendi village had the least Sensitivity score of 0.2088.

3.1.8 Testing of The Hypothesis (Lehmann et al. 2005)

The chi-square goodness of fit test was applied because there was one categorical variable from a single population. It was used to determine whether sample data were consistent with the hypothesized distribution.

It is appropriate to use the chi-square goodness of fit test when ,the sampling method is simple random sampling, the variable under study is categorical and the expected value of the number of sample observations in each level of the variable is at least 5. Four steps were used: Stating the hypotheses, Formulating an analysis plan, Analyzing sample data, and then interpreting the results.

Step 1: Stating the Hypotheses

Every hypothesis test requires the researcher to state a null hypothesis $\left(H_{0}\right)$ and an alternative hypothesis $\left(H_{a}\right)$. The hypotheses are usually stated in such a way that they are mutually exclusive. That is, if one is true, the other must be false; and vice versa.

i. $\boldsymbol{H}_{01}$ : The sensitivity of the smallholder farmers to climate related shocks in Kinakomba Ward is not significantly 
related to the number of farming and non-farming activities and other social economic characteristics.

ii. $\boldsymbol{H}_{a 1}$ : The sensitivity of the smallholder farmers to climate related shocks in Kinakomba Ward is significantly related to the number of farming and non-farming activities and other social economic characteristics. Note that for the null hypothesis to be rejected at least one of the specified proportions is not true.

Step 2: Formulating an Analysis Plan

This analysis plan describes how to use sample data to accept or reject the null hypothesis.

1.Significance Level here is equal to 0.05

2.The test Method. We used the Chi-square goodness of fit test to determine whether observed sample frequencies differ significantly from expected frequencies specified in the null hypothesis.

Step 3: Analyzing Sample Data

Using sample data we were looking for the degrees of freedom, expected frequency counts, test statistic, and the P-value associated with the test statistic.

Degrees of Freedom(DF) is equal to the number of levels $(\mathrm{k})$ of the categorical variable minus 1 : DF $=k-1$. In our case it was $2-1=1$

The expected frequency counts at each level of the categorical variable are equal to the sample size times the hypothesized proportion from the null hypothesis.

$$
\mathrm{E}_{\mathrm{i}}=n \mathrm{p}_{\mathrm{i}}
$$

where $E_{\mathrm{i}}$ is the expected frequency count for the $i$ th level of the categorical variable, $\mathrm{n}$ is the total sample size, and $\mathrm{p}_{\mathrm{i}}$ is the hypothesized proportion of observations in level $i$. In this Study:

$$
E_{1}=390 * 0.815(317.85) \quad E_{2}=390 * 0.185(72.15)
$$

Table 3.9 Observed and expected frequency counts What jobs do you and other people in your house do that bring in food or money to your house?

\begin{tabular}{|l|l|l|l|}
\hline & Observed N & Expected N & Residual \\
\hline Farming activities & 318 & 318.0 & .0 \\
Non Farming activities & 72 & 72.0 & .0 \\
Total & 390 & & \\
\hline
\end{tabular}

The test statistic is a chi-square random variable $\left(\mathrm{X}^{2}\right)$ defined by the following equation:

$$
\mathrm{X}^{2}=\Sigma\left[\left(\mathrm{O}_{\mathrm{i}}-\mathrm{E}_{\mathrm{i}}\right)^{2} / \mathrm{E}_{\mathrm{i}}\right]
$$

where $\mathrm{O}_{\mathrm{i}}$ is the observed frequency count for the $i$ th level of the categorical variable, and $E_{\mathrm{i}}$ is the expected frequency count for the $i$ th level of the categorical variable.

$$
\begin{gathered}
\mathrm{X}^{2}=\sum\left[\left(\mathrm{O}_{\mathrm{i}}-\mathrm{E}_{\mathrm{i}}\right)^{2} / \mathrm{E}_{\mathrm{i}}\right] \\
\mathrm{X}^{2}=\left[(318-317.85)^{2 / 318]}+\left[(72-72.15)^{2} / 390\right]\right. \\
\mathrm{X}^{2}=\left[(0.15)^{2 / 317.85]+\left[(-0.15)^{2} / 72.15\right]}\right. \\
=0.0000707+0.000311=0.00038
\end{gathered}
$$

where DF is the degrees of freedom, $\mathrm{k}$ is the number of levels of the categorical variable, $\mathrm{n}$ is the number of observations in the sample, $\mathrm{E}_{\mathrm{i}}$ is the expected frequency count for level $\mathrm{i}, \mathrm{O}_{\mathrm{i}}$ is the observed frequency count for level $\mathrm{i}$, and $\mathrm{X}^{2}$ is the chi-square test statistic.

The $\mathrm{P}$-value is the probability that a chi-square statistic having 1 degrees of freedom is more extreme than 0.9844 . Using the Chi-square Distribution Calculator to find $\mathrm{P}\left(\mathrm{X}^{2}>0.9844\right)=0.00038$.

Table 2.10 Chi-square test

Test Statistics

\begin{tabular}{|l|l|}
\hline & What jobs do you and other people in your house do that bring in food or money to your house? \\
\hline Chi-Square & $000^{\mathrm{a}}$ \\
df & 1 \\
Asymp. Sig. & 1.000 \\
Exact Sig. & 1.000 \\
Point Probability & .052 \\
\hline
\end{tabular}

Step 4: Interpreting Results

Since the P-value (0.00038) is less than the significance level $(0.05)$, we reject the null hypothesis. This approach is appropriate because the sampling method was simple random sampling, the variable under study was categorical, and each level of the categorical variable had an expected frequency count of at least 5.

\section{Summary of the Findings}

The study revealed that smallholder farmers who relied on farming activity alone had a sensitivity of $43.17 \%$ to climate change related shocks while those who rely on non-farming activities has a sensitivity of $36.40 \%$. When the households engage in both farming and non-farming, the sensitivity will increase by $21.20 \%$ due to the interactions between the two activities. Although the sensitivity percentage for the farmers who engaged in the two activities is low, sensitivity was statistically significant $(\mathrm{P}=0.00038)$. Further findings showed that the ratio 
of farming to nonfarming was 0.58 and those households dependent on farming and engaged in nonfarming was 0.45 and when they engage in both activities at the same time, they were more sensitive at 0.942 . Despite the significance sensitivity to climate change related shocks, farming sector was ranked as more important $(81.5 \%)$ than other livelihood activities.

\section{Conclusion}

The study concluded that sensitivity of the smallholder farmers to climate change related shock had a significant influence on their livelihoods. The study showed that the ratio of farming to non-farming related activities was 0.58 , and the extent to which households dependent on farming also engaged in non-farming livelihood activities which was 0.45 . That showed linkage between the two sectors. This revealed that the level of sensitivity decreases when many households are engaged in both occupational categories. Further the study captured the directionality of linkages between farming and non-farming activities (0.942) such that communities were more sensitive when households engaged in farming and non-farming activities and continued consistently ranking the farming sector as more important $(81.5 \%)$ than other livelihood activities. Using this composite metric, we captured some new aspects of sensitivity that at 0.2458 the community has a low sensitivity ratio. Secondly the ratio of the total number of households to the total number of occurrences of households being engaged in either the farm or non-farm sector was 0.45 meaning the level of sensitivity decreased when many households engaged in both occupational categories. Thirdly the ranking of occupational importance was also taken into account. This was designed to differentiate between cases when farming is being ranked higher than non-farming and the other way round, the researcher found out that the score for Kinakomba Ward here was 0.942. Since the farming sector was ranked higher at $81.5 \%$, the sensitivity index decreased to 0.2 .

Other conclusions included:

i. $\quad$ Farming among smallholder farmers is practiced by both sexes and women are sensitive to functions of food production which are affected by climate related shocks. Women are also sensitive to nutritional needs of their families

ii. Agricultural sector is most sensitive to changing climatic conditions which affect agricultural production and farming communities

iii. Smallholder farmers are one of the most vulnerable social groups to climate change

iv. Climate related shocks have negative impacts on agricultural production of farmers and put farmers households well-being and food security at risk

v. Two thirds of farmers were young and energetic and could bring positive change in agricultural production. Thus smallholder farmers are less sensitive to other production factors because of their average young age

vi. Residents were lowly educated meaning they could not follow well agricultural trainings provided by different stakeholders( $44.9 \%$ illiteracy rate). Lack of ability to follow such trainings increases the sensitivity of the smallholder farmers

vii. Inadequate education is a key factor that shapes vulnerability, low level of education of household heads affects the livelihoods options that a household engages in

viii. Smallholder farmers ranked farming higher than any other activities making them more sensitive to climate related shocks because they may not have anything to fall back to in case of severe drought, frequent floods nor pest outbreak

ix. The community was also abandoning farming because farming had become expensive(inputs), land was becoming less productive because of soil infertility, irrigation was expensive because of fossil fuels and no markets for their products. They are getting trapped in debts and cycle of poverty

x. Sensitivity reduces when farmers get involved in diversification within farming like kitchen gardening, agroecological approaches, livestock keeping since in case of unpredictable climate related shocks they have something to fall back to.

xi. Majority of smallholder farmers were involved in decision making About their farming activities . this reduces their sensitivity to climate related shocks since it enables them to determine their destiny effectively reducing their most pressing problems.

xii. Being involved in groups also reduces their sensitivity because a problem shared is half-way solved. Through groups they know how to take care of their produce, what their harvest is, how much it costs, this empowers them and reduces their sensitivity to negative impacts of climate related shocks.

xiii. This also addresses the attitudes of farmers through discussions they are able to address the negative attitudes towards climate friendly crops that are good for their health as well as their food security.

\section{Recommendations}

The Study recommended that the County Government in partnership with stakeholders develops interventions of adaptation options and empowerment of farmers with skills in diversification of livelihoods options. These 
recommendations included:

i. $\quad$ Farmers need to be encouraged to form groups so that they can solve their immediate problems

ii. Stakeholders need to support farmers in trainings that are geared towards climate related shocks

iii. Stakeholders need to support innovative irrigation methods using unconventional ways like solar and wind powers which are available and in plenty in the study area.

iv. The Government and stakeholders to provide a policy of establishing small village manageable irrigation schemes for the rural poor communities that can address the immediate food security needs as well as focusing on addressing diversifying the livelihoods base at the grassroot

v. The Government and Stakeholders to provide policy on cottage industries for the produce of such irrigation schemes which will provide market and storage at the local level

vi. The Government to provide support and policy for establishing smallholder farmers Cooperatives to empower them at the village level

vii. The Government to have a policy of registration of smallholder farmers so that they can access government support systematically including devolved funds and affordable loans

\section{References}

Adejuwon, J. O.(2008). Vulnerability in Nigeria, a national level assessment. In Leary, N., Conde, C., Kulkarni, J., Nyong, A. and Pulhin, J. (eds). Climate Change and Vulnerability. Earthscan, London, UK, pp. 198-217.

Adger, W Neil, Shardul Agrawala, M Monirul Qader Mirza, Cecilia Conde, Karen O’Brien, Juan Pulhin, Roger Pulwarty, Barry Smit, and Kiyoshi Takahashi. 2007. Assessment of Adaptation practices, options, constraints and capacity. Climate Change: 717-743.

Adger,W.N.; Dessai, S.; Goulden, M.; Hulme, M.; Lorenzoni, I.; Nelson, D.R.; Naess, L.O.;Wolf, J.;Wreford, A. Are there social limits to adaptation to climate change? Climate. Change. 2009, 93, 335-354.

Alam, M.M., Siwar, C., Talib, B.A., Wahid, A.N., 2017. Climatic changes and vulnerability of household food accessibility: a study on Malaysian east coast economic region. Int. J. Clim. Change Strategies Manage. 9.

Allison, E.H., Perry, A.L., Badjeck, M.C., Adger, W.N., Brown, K., Conway, D., Halls, A.S.,Pilling, G.M., Reynolds, J.D., Andrew, N.L., Dulvy, N.K., (2009). Vulnerability of national economies to the impacts of climate change on fisheries. Fish and Fisheries 10, 173-196.

Brundtland Commission, (1987), "Our Common Future", Oxford University Press.

Birkmann J, Garschagen M, Mucke P, Schauder A, Seibert T, Welle T, Rhyner J, Kohler S, Loster T, Reinhard D, Matuschke I (2014) World Risk Report 2014. Bündnis Entwicklung Hilft and UNUEHS doi:10.1126/science.79.2037.38. PMID 17813446.

Bollin C, Hidajat R (2006) Community-based disaster risk index: pilot implementation in Indonesia, towards disaster resilient societies. In: Birkmann J (ed) Measuring vulnerability to natural hazards. UNU-Press, Tokyo, New York, Paris

Chinwendu, O.G., Sadiku, S., Okhimamhe, A., Eichie, J., 2017. Households vulnerability and adaptation to climate variability induced water stress on downstream Kaduna River Basin American. J. Clim. Change 6, 247.

Cronbach LJ (1951). "Coefficient alpha and the internal structure of tests". Psychometrika 16 (3): $297-334$.

FAO (2014). Adapting to climate change through land and water management in Eastern Africa: Results of pilot projects in Ethiopia, Kenya and Tanzania. Rome, Italy: Food and Agriculture Organization of the United Nations. http://bit.ly/1sbPHr5.

Garschagen M., (2014) Risky change? Vulnerability and adaptation between climate change and transformation dynamics in Can Tho City, Vietnam. Steiner 15, Stuttgart

IPCC, (2010),"Assessment of adaptation practices, options, constraints and capacity" (PDF). Archived (PDF) from the original on 27 August 2010. Retrieved 2010-08-29.

Jan, I., Khattak, M.K., Khan, M.A., Hayat, S., Rahim, T., 2012. Factors affecting rural livelihood choices in Northwest Pakistan Sarhad. J. Agric. 28.

J.E. Cinner et al., (2012): Vulnerability of coastal communities to key impacts of climate change on Coral reef fisheries / Global Environmental Change 22 (2012) 12-20

Kloos J, Asare-Kyei D, Pardoe J, Renaud FG., (2015): Towards the development of an adapted multi-hazard risk assessment framework for the West Sudanian Savanna Zone. UNU- EHS Publication 11:4-26

Lehmann, E. L.; Romano, Joseph P. (2005). Testing Statistical Hypotheses (3E ed.). New York: Springer. ISBN 978-0-387-98864-1

Levin, S., Xepapadeas, T., Crépin, A., Norberg, J., De Zeeuw, A., Folke, C., Hughes, T., Arrow, K., Barrett, S., Daily, G., Ehrlich, P., Kautsky, N., Mäler, K., Polasky, S., Troell, M., Vincent, J.R. and Walker, B., (2013). Social-ecological systems as complex adaptive systems: modeling and policy implications. Environment and Development Economics, 18(02): 111.

Lindoso, D.P., Rocha, J.D., Debortoli, N., Parente, I.C.I., Eiró, F., Bursztyn, M., Rodrigues Filho, S., 2012. Indicators for Assessing the Vulnerability of Smallholder Farming to Climate Change: the Case of Brazil, 
Semi-Arid Northeastern Region.

Mansur AV, Brondizio ES, Roy S, Hetrick S, Vogt N, Newton A.,(2016) An assessment of urban vulnerability in the Amazon Delta and Estuary: a multi-criterion index of flood exposure, socio-economic conditions and infrastructure. Sust Sci. doi:10. 1007/s11625-016-0355-7

Mbakahya, G., Ndiema, A., 2015. Farming households' vulnerability and resilience to climate change in Nambale sub-county of Kenya. Int. J. Sci. Environ. Technol. 4, 1608-1617.

Menike, L., Arachchi, K.K., 2016. Adaptation to climate change by smallholder farmers in rural communities: evidence from Sri Lanka. Procedia Food Science 6, 288-292.

McGinnis, M.D.,\& Ostrom, E. (2014).Social ecological system framework: initial changes and continuing challenges. Ecology and Society,19(2)(30),06387 190230.

Ndegwa, Peter et.al.,(2015): Assessment of Factors Influencing Food Security in Wenje Division, Tana River County - Kenya, in: Food Science and Quality Management, Vol.44. http://www.iiste.org/Journals/index.php/FSQM/issue/view/2112 [accessed 4 February, 2018]

Nyong, A., Dabi, D., Adepetu, A., Berthe, A. \& Ihemegbulem, V. C.,(2008). Vulnerability in the Sahelian zone of northern Nigeria, a household level assessment. In Leary, N., Conde, C., Kulkarni, J., Nyong, A. and Pulhin, J. (eds). Climate Change and Vulnerability. Earthscan, London, UK.

Ohl, C., Krauze, K. and GrünbüheL, C., (2007). Towards an understanding of long-term ecosystem dynamics by merging socio-economic and environmental research: Criteria for long-term socio-ecological research sites selection. Ecological Economics, 63(2-3): 383-391.

Ostrom E.,( 2007).A diagnostic approach for going beyond panaceas. Proceedings of the National Academy of Sciences 104 (39):15181-15187. http://dx.doi.org/10.1073/pnas.0702288104

Ostrom, E.,(2009). A general framework for analyzing sustainability of social-ecological systems. Science, 325(5939), 419-422

Pulhin, J. M., Peras, R., Cruz, R., Lasco, R., Pulhin, F. and Tapia, M.,(2008). Climate variability and extremes in the Pantabangan-Carranglan watershed of the Philippines, an assessment of vulnerability. In Leary, N., Conde, C., Kulkarni, J., Nyong, A. and Pulhin, J. (eds). Climate Change and Vulnerability. Earthscan, London, UK.

Republic of Kenya., (2013) National Climate Change Action Plan 2013 - 2017. Nairobi, Kenya: Government of Kenya. http://bit.ly/1AkMWsU.

Saltelli, A., Ratto, M., Andres, T., Campolongo, F., Cariboni, J., Gatelli, D. Saisana, M., and Tarantola, S., 2008, Global Sensitivity Analysis. The Primer, John Wiley \& Sons

Sebesvari Z, Renaud FG, Haas S, Tessler Z, Hagenlocher M, Kloos J, Szabo S, Tejedor A, Kuenzer C., A review of vulnerability indicators for deltaic social-ecological systems, (2016), Sustain Sci DOI 10.1007/s11625016-0366-4

Sobol,I.M. (2001), Global sensitivity indices for nonlinear mathematical models and their Monte Carlo estimates. MATH COMPUT SIMULAT,55(1-3),271 280, doi:10.1016/S0378-4754(00)00270-6

UN (United Nations), (2009): Global Assessment Report on Disaster Risk Reduction. Risk and poverty in a changing climate United Nations, Geneva

UN (United Nations), (2011):Global Assessment Report on Disaster Risk Reduction. Revealing risk, redefining development United Nations, Geneva

UN (United Nations), (2013):Global Assessment Report on Disaster Risk Reduction 2013. From Shared Risk to Shared Value: the Business Case for Disaster Risk Reduction. United Nations, Geneva

United Nations Framework Convention on Climate Change (2013). Workshop on the Monitoring and evaluation of adaptation, Nadi, Fiji, 9-11 September 20 [Background Note].Bonn, Germany: Author. http://unfccc.int/files/adaptation/cancun_adaptation_framework/adaptation_committee/applicatio n/pdf/ac_m\&e_ws_background_note_16 $\overline{6}$ august2013.pdf Uphoff, N. (1993) Grassroots Organizations and NGOs in Rural Development: Opportunities with Diminishing States and Expanding Markets, World Development, 21(4): 607-22.

Ziervogel, G., Nyong, A., Osman, B., Conde, C., Cortés, S. and Downing, T.,(2008). Climate Variability and Change: Implications for Household Food Security. AIACC Working Paper No. 20, January 2006. 32 pp. Internet file retrieved on 17th August 2011 from http:// www.aiaccproject.org/working_papers/Working\%20Papers/AIACC_WP_20_Ziervogel.pdf. 